\title{
PENERAPAN METODE FLOTASI UNTUK MEREDUKSI KADAR URANIUM YANG ADA DALAM AIR LIMBAH SIMULASI
}

\author{
Ign. Djoko Sardjono, Prayitno dan Herry Poernomo \\ Puslitbang Teknologi Maju Batan, Yogyakarta.
}

\begin{abstract}
ABSTRAK
Te/ah dilakukan penelitian terapan metode flotasi untuk mereduksi kadar uranium dalam air limbah. Penelitian ini bertujuan untuk mengetahui keefektifan dari metode flotasi dalam menurunkan kadar unsur/radionuklida uranium yang berpotensi mencemari lingkungan. Keefektipan dari metode flotasi dikaji secara eksperimental dengan melihat parameter proses yang berpengaruh dalam penuruan kadar uranium dalam air limbah setelah melalui tahapan kopresipitasi yang dilanjutkan dengan proses flotasi. Parameter proses yang dipakai sebagai ukuran keefektipan penurunan kadar uranium ialah volume bahan kolektor natrium oleat, $\mathrm{pH}$ proses, serta volume bahan frother tetra etl/en glikol/TEG $\left(\mathrm{C}_{8} \mathrm{H}_{18} \mathrm{O}_{5}\right)$ yang ditambahkan yang menghasilkan efisiensi rekoveri ( $\mathrm{R}$ dalam \%) tertinggi. Percobaan proses dilakukan secara catu (batch) dengan umpan limbah simulasi uranium tetap $=100$ ppm dan kadar kopresipitan Fe(IIl) dan Al(III) tetap $=100$ ppm; pH divariasi dari $4-12$, volume kolektor natrium oleat $\left(\mathrm{C}_{18} \mathrm{H}_{33} \mathrm{O}_{2} \mathrm{Na}\right)$ divariasi dari $=10$ - $45 \mathrm{ml}$ dan TEG divariasi dari 10 - 30 tetes. Dari perlakuan tersebut di atas diperoleh data adanya kenaikan $R$ dengan adanya penambahan volume kolektor na-oleat dari $=10-45 \mathrm{ml}$ dengan $R$ terbesar $=94,56 \%$; sedangkan untuk kopresipitan Al(III) dengan jumlah kolektor dan frother yan/g sama diperoleh $R$ terbesar $=96,4 \%$ Sehingga dapat disimpulkan bahwa R(u) naik dengan kenaikan volume dan kadar kolektor serta volume frother dengan nilai maksimum $=96,4 \%$ dicapai pada $p H=11$ dan jumlah kolektor $=30 \mathrm{ml}$ serta frothernya $=0,50 \mathrm{ml}$.
\end{abstract}

\begin{abstract}
Applied inv'estigation for the flotation methods has been conducted on the reduction of uranium concentration in the waste water. This investigation aims at determining the effectiveness of flotation methods in reducing the concentration of uranium element/radionuclide that potentially contaminates the environment. The effectiveness of flotation methods was experimentally assessed by investigating the process parameters affect on the reduction of uranium concentration in the waste water after being passed on coprecipitation step and was proceeded to the flotation process. The process parameters used as the effectiveness of reducing the cocentration of uranium are the volume of sodium oleate collector, $\mathrm{pH}$; as well as the volume of tetra ethylene glycol (TEG) as the frother added that resulted in the highest recovery efficiency ( $R$ in \%). The experimental process was conducted batch wisely with the constant simulated waste feed of $100 \mathrm{ppm}$ and the coprecipitant concentration $\mathrm{Fe}(\mathrm{III})$ and $\mathrm{Al}(\mathrm{III})$ of $100 \mathrm{ppm}$; $\mathrm{pH}$ was varied from 4 - 2, the volume of sodium oleate collector $\left(\mathrm{CH}_{3}-\left(\mathrm{CH}_{2}\right)_{7} \mathrm{CH}=\mathrm{CH}\right.$ $\left(\mathrm{CH}_{2}\right)_{7}$-COONa) was varied from $10-45 \mathrm{ml}$ and TEG was varied from $10-30$ drops. From the treated waste above was obtained the trend data of increasing $R$ due to the addition of sodium oleate collector volume from $10-45 \mathrm{ml}$ with $R=94.56 \%$, whereas for the coprecipitant Al(III) by the same amount of collector and frother yielded the largest $R=96.4 \%$ at $p H=11$ and the amount of collector $=30 \mathrm{ml}$ as well as the frother $=0.50 \mathrm{mI}$.
\end{abstract}

\section{PENDAHULUAN}

$\mathrm{P}$ enelitian ini dilakukan dengan tujuan untuk menerapkan metode flotasi dalam pengolahan limbah cair radioaktif, yang menurut YOSHIO KOY ANAKA ${ }^{(1)}$ dalam Studies on the Treatment of Radioactive
Liquid Wastes by Flotation Method, JAERI, March 1967, ini dikenal ada dua mekanisme : pertama ialah peran dari gelembung terhadap unsur-unsur metalik radioaktif terlarut dalam air limbah yang jumlahnya relatif kecil yang dipengaruhi oleh sifat fisiko -kimia dari antar fase cair dan gas, 
dan kedua ialah yang dipengaruhi oleh sifat fisiko - kimia dari antar fase padat-cair-gas.

Sedangkan menurut DONALD W.SUNDSTROM \& HERBERT E.KLEI ${ }^{(2)}$, BARD I MURACHMAN ${ }^{(3)}$, ROBERT H.PERRY AND DON W.GREEN ${ }^{(4)}$ untuk flotasi merupakan prosedur pemisahan padat-cair atau cair-cair yang diterapkan pada partikel yang densitasnya lebih rendah daripada densitas cairan dimana partikel tersebut berada yang diklasifikasikan sebagai flotasi alami/natural bila selisih densitas sangat cukup untuk pemisahan, flotasi Aided terjadi bila digunakan sarana eksternal digunakan untuk mempromosikan pemisahan partikel yang secara alami bisa mengalami flotasi dan flotasi secara induksi terjadi bila densitas dari partikel aslinya lebih tinggi daripada densitas cairan dan secara artifisial dibuat lebih rendah. Hal ini didasarkan pada kapasitas padatan dan partikel cairan untuk bergabung dengan gas (biasanya udara). Dalam metode pemisahan buih dengan ketentuan bahwa mekanisme yang terjadi didominasi oleh peran dari gelembung terhadap unsur-unsur metalik radioaktif terlarut dalam air limbah yang jumlahnya relatif kecil yang dipengaruhi oleh sifat fisika - kimia dari antar fase cair dan gas, dan ini yang utama digunakan untuk ion-ion metalik yang mudah membentuk senyawa komplek dengan aktivator permukaan. Untuk aktivator permukaan menurut RICHARD P.H., AMIR E., TUKARDI, SRI SUDARY ANTO $^{(5)}$

dan

Http://www.exploratorium.edu/ronh/bubble s/soap.html ${ }^{(6)}$ dan bisa dipakai senyawa organik yang mempunyai sifat heteropolar misalnya natrium oleat dan tetra etilen glikol yakni dengan gugus polar yang suka air dan menempel pada senyawa polar misalnya air dan gugus non polar yang nantinya bisa menempel pada gelembung udara atau buih yang terbentuk pada proses flotasi yang bisa mengapungkan partikel padat dari unsur logam pengotor yang ada dalam air limbah. Metode ini telah. berhasil penggunaannya (dengan ditandai oleh faktor dekontaminasinya yang sangat baik untuk memungut kembali unsur-unsur radioaktif seperti Cs-137, Sr-90, Ce-144 dan Ra-226 serta molibdenit $\left(\mathrm{MoS}_{2}\right)$ dari air limbah pabrik uranium. Berdasarkan pernyataan ,di atas dicoba untuk diterapkan metode ini untuk mereduksi kadar uranium dalam air limbah dengan menggunakan natrium oleat sebagai kolektor dan tetra etilen glikol sebagai frother setelah melewati tahap kopresipitasi dengan menggunakan feri nitrat dan aluminium nitrat sebagai kopresipitan. Diharapkan dengan metode ini bisa meningkatkan keefektipan pengolahan limbah yang mengandung uranium.

\section{TAT A KERJA}

\section{Bahan yang digunaka}

Limbah simulasi uranium dari larutan $\mathrm{UO}_{2}\left(\mathrm{NO}_{3}\right)_{2} \cdot 6 \mathrm{H}_{2} \mathrm{O}$, bahan kopresipitan larutan $\mathrm{Fe}\left(\mathrm{NO}_{3}\right)_{3}$ dan $\mathrm{Al}\left(\mathrm{NO}_{3}\right)_{3}$ dengan kadar 100 ppm, Bahan kolektor Na-Oleat $\left(\mathrm{C}_{18} \mathrm{H}_{33} \mathrm{O}_{2} \mathrm{Na}\right)$ dengan kadar 100 ppm, Bahan frother tetra etilcn glikol $\left(\mathrm{C}_{8} \mathrm{H}_{18} \mathrm{O}_{5}\right)$ 0,25-0,75 ml, Larutan $\mathrm{KOH} 0,1 \mathrm{~N}$ untuk pengkondisian $\mathrm{pH}$.

\section{Alat yang digunakan}

Bekerglas dengan kapasitas $250 \mathrm{ml}$, batang pengaduk magnetik dengan diameter $5 \mathrm{~cm}$, Stop watch untuk pengamatan waktu pengadukan, timbangan Sartorius untuk penimbangan berat bahan penelitian, unit flotasi dengan kapasitas $200 \mathrm{ml}$, unit pemompa udara (aerator) ukuran $300 \mathrm{~mA}$, Spectronic-20 untuk menganalisis kadar uranium sebelum dan sesudah proses

Skema peralatan proses dapat digambarkan dalam Gambar 1 berikut: 


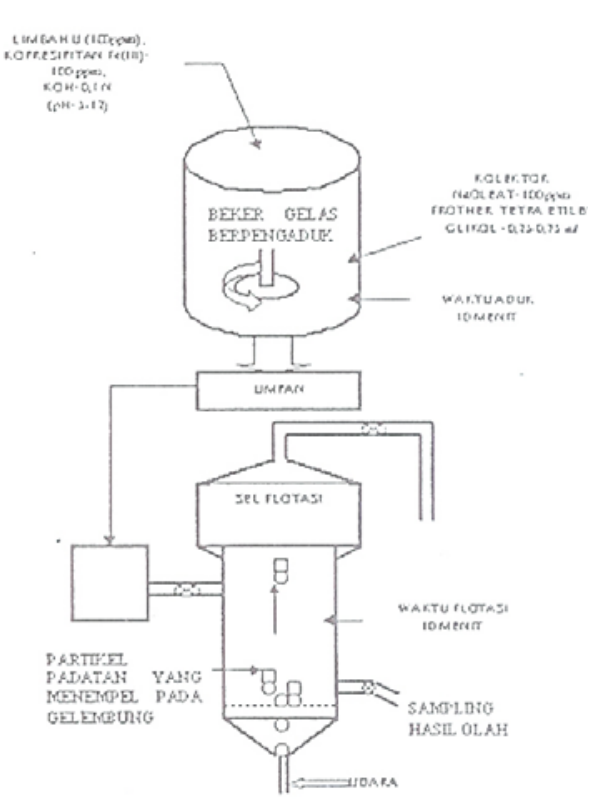

Gambar 1. Skema Percobaan Flotasi

\section{Cara Kerja}

1. Siapkan larutan uranium dengan kadar 100 ppm sebanyak $100 \mathrm{ml}$. sebagai umpan limbah simulasi, kemudian masukkan umpan terscbut ke dalam gclas beker $250 \mathrm{ml}$.

2. Ke dalam limbah tersebut ditambahkan kopresipitan larutan $\mathrm{Fe}(\mathrm{III})$ dengan kadar 500 ppm sebanyak $2 \mathrm{ml}$,

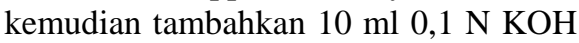
dan diaduk cepat selama 10 menit.

3. Sctelah ada indikasi terjadinya pcngendapan $\mathrm{Fe}(\mathrm{III})$ tcrsebut bersama dengan uranium,

4. kemudian ditambah $2,5 \mathrm{ml}$ larutan 100 ppm kolektor Na-oleat dan frother .tetra etilen glikol beberapa ml. Untuk selanjutnya dimasukkan ke dalam unit sel flotasi dan diairasi selama 10 menit.

5. Setelah proses flotasi selesai, diambil 10 $\mathrm{ml}$ cuplikan limbah untuk dianalisis kadar uranium sisa yang ada dalam larutan. Dari data kadar uranium sisa dan kadar uranium awal dapat dihitung hasil rekoveri uranium dalam \% berdasar korelasi $\mathrm{R}=$ (1-T.t/F.f)x100\% dengan $\mathrm{R}=$ hasil rekoveri $\mathrm{U}, \mathrm{f}=$ kadar $\mathrm{U}$ dalam limbah awal/sebelum diflotasi, $\mathrm{F}$ $=$ volume limbah awal, $\mathrm{t}=$ kadar $\mathrm{U}$ setelah proses flotasi dan $\mathrm{T}=$ volume limbah setelah proses flotasi.

6. Langkah yang sama dengan percobaan nomer urut 1 sampai dengan 4 diterapkan pada percobaan lanjut untuk variasi $\mathrm{pH}$ dari 4-12 dengan parameter jumIah kolektor tetap $2 \mathrm{ml}$ dan frother tetap $0,5 \mathrm{ml}$.

7. Langkah yang sama dengan percobaan nomer urut 1 sampai dengan 4 diterapkan pada percobaan lanjut untuk variasi jumlah kolektor 2,5 ml - $45 \mathrm{ml}$ dengan parameter jumlah frother tetap $0,125 \mathrm{ml}$ dan $\mathrm{pH}=11$.

8. Langkah yang sama dengan percobaan nomer urut 1 sampai dengan 4 diterapkan pada percobaan lanjut untuk variasi jumlah frother $0,25 \mathrm{ml}-0,75 \mathrm{ml}$ dengan parameter jumlah kolektor tetap $30 \mathrm{ml}$ dan $\mathrm{pH}=11$.

9. Langkah yang sama dengan percobaan nomer urut 1 sampai dengan 4 diterapkan pada percobaan lanjut untuk kenaikan kadar kolektor Na-Oleat (ppm) dari 120 - 160 ppm untuk 100 ppm limbah uranium yang telah dikopresipitasikan dengan $\mathrm{Al}(\mathrm{III})$ pada $\mathrm{pH}=11$.

\section{HASIL DAN PEMBAHASAN}

\section{Korelasi kenaikan nilai pH larutan limbah dan recovery uranium, $R_{u}(\%)$}

Data percobaan flotasi dengan memvariasikan nilai $\mathrm{pH}$ larutan limbah dari $\mathrm{pH}=4-12$ dengan kopresipitan $\mathrm{Al}(\mathrm{III})$ berkadar 500 ppm untuk limbah simulasi uranium berkadar 100 ppm dapat dilihat dalam Gambar 2. Dalam Gambar 2 dapat dilihat kecenderungan naiknya recovery uranium dengan kenaikan nilai $\mathrm{pH}$ dengan nilai maksimunmya $\mathrm{R}_{\mathrm{u}}=96,4 \%$ pada $\mathrm{pH}=\mathrm{ll}$, meskipun ada penurunan pada $\mathrm{pH}$ sekitar 9 yang disebabkan oleh lepasnya ikatan 
gelembung dengan partikel padatan sehingga menurunkan efektifitas proses flotasi yang seharusnya terjadi. Hal ini bisa terjadi karena ikatan yang terjadi antara gelembung dan pertikel endapan yang dominan adalah ikatan fisik antara gugus non-polar yang ada dalam partikel endapan dengan udara.

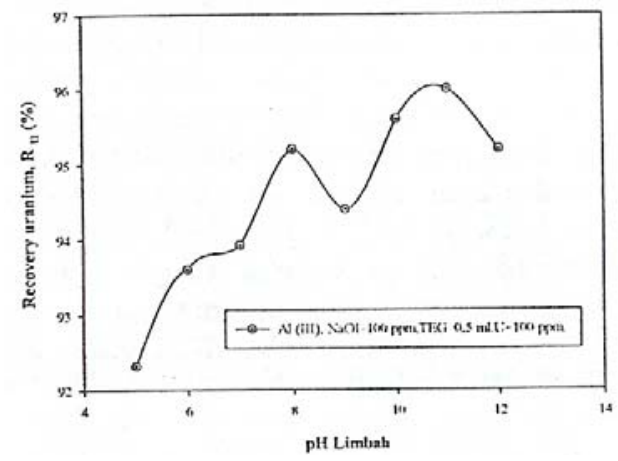

Gambar 2. Korelasi kenaikan nilai $\mathrm{pH}$ dan recoveri uranium, $\mathrm{R}_{\mathrm{u}}(\%)$

\section{Korelasi penambahan volume kolektor Na-oleat dan recoveri uranium, $R_{u}(\%)$}

Data percobaan flotasi dengan memvariasikan volume kolektor natrium oleat dari 2,5 ml sampai dengan $45 \mathrm{ml}$ pada kopresipitan $\mathrm{Fe}(\mathrm{III})$ dan $\mathrm{Al}(\mathrm{III})$ berkadar 500 ppm setelah melewati tahapan pengkondisian $\mathrm{pH}=11$ untuk limbah simulasi uranium berkadar $100 \mathrm{ppm}$ dapat dilihat dalam Gambar 3. Dalam Gambar 3 dapat dilihat kecenderungan naiknya recoveri uranium, untuk kopresipitan Fe(III) mulai $\mathrm{R}_{\mathrm{u}}=92 \%$ sampai nilai maksimunmya $=93,6 \%$ setelah kolektornya mencapai penambahan volume $=35 \mathrm{ml}$ meskipun tidak signifikan. Sedangkan untuk kopresipitan Al (III) mulai $\mathrm{R}_{\mathrm{u}}=92,2 \%$ sampai nilai maksimunya $=94,6 \%$ setelah kolektornya mencapai penambahan volume = $30 \mathrm{ml}$. Dengan demikian ada kenaikan 1 digit pada pemakaian kopresipitan Al(III) dibandingkan dengan Fe(III).

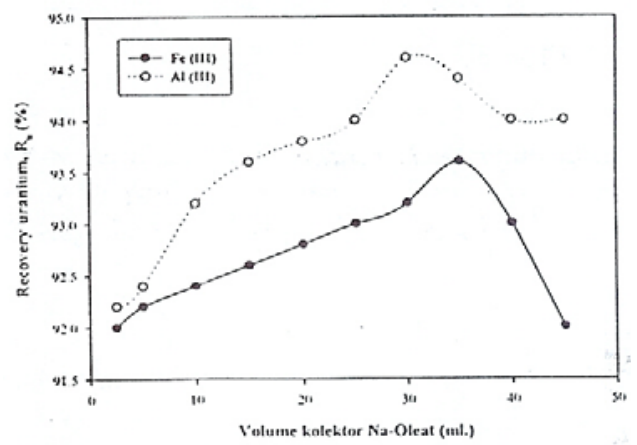

Gambar 3. Koreksi penambahan volume kolektor Na-Oleat (ml) dan recoveri uranium, $\mathrm{R}_{\mathrm{u}}(\%)$

Perbedaan yang tidak signifikan ini disebabkan oleh tingkat valensi yang sama dari $\mathrm{Al}$ (III) dan Fe (III) juga tingkat polarisitas dari kolektor yang tinggi sehingga ikatan yang terjadi antara buih yang ditimbulkan oleh naiknya gelembung udara pada partikel padatan uranium yang terkopresipitaskan oleh baik $\mathrm{Al}$ (III) dan Fe (III), melalui proses flotasi tidak terlalu massif dan akibatnya masih cukup banyak uranium yang lebih suka berada dalam larutan sehingga nilai $\mathrm{R}_{\mathrm{u}}$ relatif masih rendah (dibawah 99\%). Bahkan terlihat adanya penurunan yang disebabkan karena kestabilan gelembung relatif rendah sehingga mudah pecah dan partikel yang seharusnya terangkat dalam proses flotasi menjadi terlarut kembali dalam larutan limbah.

\section{Korelasi penambahan volume frother tetra etilen glikol (TEG) dan recoveri uranium, $\mathbf{R}_{\mathbf{u}}(\%)$.}

Data penambahan volume frother TEG dari 0,25 sampai dengan $0,75 \mathrm{ml}$ setelah pengkopresipitasian dengan 100 ppm Fe(III) untuk recovery 100 ppm uranium pada $\mathrm{pH}=12, \quad 30 \mathrm{ml}$ kolektor Na-oleat justru cenderung menurunkan $\mathrm{R}_{\mathrm{u}}$ dari 95,52 - 92,8 (\%) seperti dapat dilihat dalam Gambar 4 dan terbaik diperoleh pada penambahan frother sebanyak $0,25 \mathrm{ml}$. 


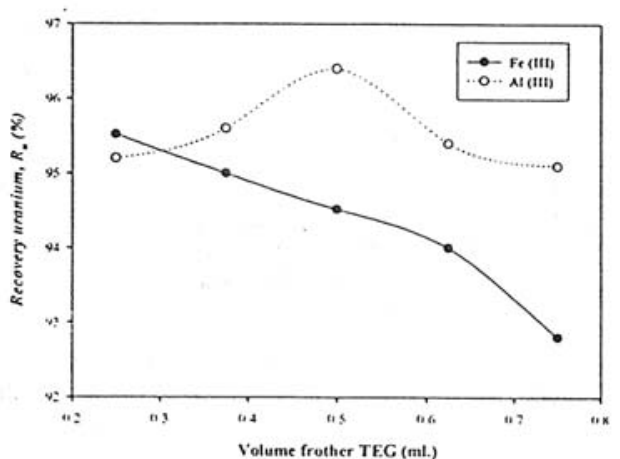

Gambar 4. Korelasi penambahan volume frother TEG (ml) dan recoveri uranium $\mathrm{R}_{\mathrm{u}}(\%)$

Sedangkan untuk kopresipitan Al(III) semula ada kecenderungan menaik dari 95,2 - 96,4 pada penambahan frother 0,25-0,5 $\mathrm{ml}$. Tetapi setelah penambahan frother dari 0,625 - 0,75 ml. Terjadi penurunan $\mathrm{R}_{\mathrm{u}}$ dari 95,40 - 95,1. Fenomena yang terjadi mungkin disebabkan terjadinya penurunan daya penstabilan buih yang diharapkan bisa berperan dalam penurunan tegangan muka air sebagai akibat terjadinya koalesensi atau penggabungan gelembung kecil menjadi besar sehingga kecepatan apungnya menjadi lebih tinggi dan kontak dengan partikel endapan yang seharusnya diikat oleh gugus non-polar terlalu singkat, sehingga uranium yang seharusnya terikut pada proses flotasi justru cenderung tetap tinggal dalam larutan. Untuk Al yang relatif lebih ringan dari pada $\mathrm{Fe}$; ternyata juga memberikan trend yang berbeda sepcrti tcrlihat pada Gambar 4 dimana keterikatan gugus non polar partikel cndapan Al pada gelembung lebih kuat dibandingkan dengan Fe, sehingga efektifitas f1otasi Al lebih besar dari pada Fe dan akibatnya $\mathrm{R}_{u}(\%)$ untuk $\mathrm{Al}$ mengalami kenaikan, sedangkan $\mathrm{R}_{\mathrm{u}}$ (\%) untuk Fc mongalami pcnurunan dengan penambahan TEG sebagai frother yang berfungsi sebagai penstabil buih.

\section{Korelasi kenaikan kadar kolektor Na- Oleat (ppm) dan recoveri uranium, $R_{u}$ (\%)}

Data kenaikan kadar kolektor NaOleat (ppm) dari 120 - 160 ppm untuk 100 ppm limbah uranium yang telah dikopresipitasikan dengan $\mathrm{Al}(\mathrm{III})$ pada $\mathrm{pH}=12$ memperlihatkan kecenderungan naik pada penambahan kolektor Na-Oleat dari 130 - 150 ppm dan mencapai maksimum pada penambahan kolektor $=150 \quad$ ppm dengan $R_{u}=96,4 \%$ seperti dapat dilihat dalam Gambar 5.

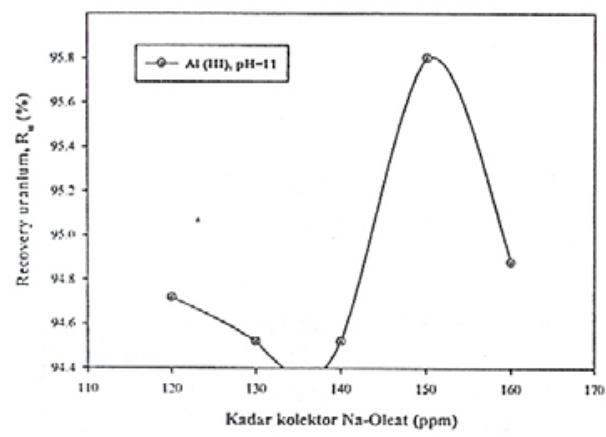

Gambar 5. Korelasi kenaikan kadar kolektor Na-Oleat (ppm) dan recovery uranium, $\mathrm{R}_{\mathrm{u}}(\%)$.

Ternyata penambahan kadar kolektor Na-Oleat juga bisa menaikan nilai recovery uranium meskipun tidak signifikan. Hal ini disebabkan oleh penambahan jumlah gugus non polar yang aktif dari Na-Oleat sebagai bahan kolektor sebagai gugus pengikat antara partikel uranium yang dikopresipitasikan dengan $\mathrm{Al}(\mathrm{III})$ dengan gelembung udara yang membentuk buih dengan kolektor sehingga flotasi partikel padatan terjadi. Meskipun demikian dengan penambahan volume kolektor Na-Oleat diharapkan ada kenaikan $\mathrm{R}_{\mathrm{u}}$, tetapi ternyata seperti terlihat dalam Gambar 5 pada penambahan volume $130-140 \mathrm{ml}$ Na-Oleat $\mathrm{R}_{\mathrm{u}}$ menurun yang disebabkan oleh lepasnya 
sebagian partikel endapan yang terikat gelembung sehingga flotasi tidak maksimal.

\section{KESIMPULAN}

Dari data yang diperoleh pada percobaan yang dilakukan dapat ditarik beberapa kesimpulan sebagai berikut:

1. Hasil recoveri uranium dalam air limbah naik dengan kenaikan nilai $\mathrm{pH}$ yang menghasilkan nilai recoveri uranium maksimum dicapai pada $\mathrm{pH}=11$ dengan $\mathrm{R}_{\mathrm{u}}=96,4 \%$ untuk kopresipitan Al(III) dalam proses flotasi selama 10 menit.

2. Hasil recovery uranium dalam air limbah naik dengan penambahan volume kolektor Na-oleat dan maksimum dicapai pada penambahan $30 \mathrm{ml}$ dengan $\mathrm{R}_{\mathrm{u}}=94,6 \%$ untuk kopresipitan Al(III) dalam proses flotasi selama 10 menit.

3. Hasil recovery uranium dalam air limbah naik dengan penambahan volume frother tetra etilen glikol dan maksimum dicapai pada penambahan $0,5 \mathrm{ml}$ dengan $\mathrm{R}_{\mathrm{u}}=$ 96,4 \% untuk kopresipitan Al(III) dalam proses flotasi selama 10 menit.

4. Hasil recovery uranium dalam air limbah naik dengan penambahan kadar Na-oleat dan maksimum dicapai pada penambahan $150 \mathrm{ppm}$ dengan $\mathrm{R}_{\mathrm{u}}=96,4$ $\%$ untuk kopresipitan Al(III) dalam proses flotasi selama 10 menit.

5. Kopresipitan $\mathrm{Al}(\mathrm{III})$ lebih baik dari pada kopresipitan $\mathrm{Fe}(\mathrm{III})$ dalam menghasilkan recovery uranium.

\section{UCAPAN TERIMA KASIH}

Penelitian ini tidak bisa terwujud tanpa bantuan dari Sdr. Tri Suyatno dan Sdr. Wasim Yuwono, AMd. keduanya Staf Subid. Pengelolaan Limbah dan Keselamatan Lingkungan, Bidang Keselamatan dan Kesehatan, Puslilbang Teknologi Maju BATAN Yogyakarla dan Sdr. Isa Anshori, Staf dari Balai Elektro Mekanik Puslitbang Teknologi Maju BATAN Yogyakarta yang telah membantu dalam pembuatan alat penelitian serta dana dari Proyek Pengembangan Teknologi Limbah Nuklir Untuk Pengamanan Manusia dan Lingkungan, P2PLR Serpong, untuk kesemuanya itu kami mengucapkan terima kasih.

\section{DAFTAR PUSTAKA}

1. YOSHIO KOY ANAKA, Studies on the Treatment of Radioactive Liquid Wastes by Flotation Method, JAERI, March (1967).

2. DONALD W. SUNDSTROM \& HERBERT E.KLEI ,Waste water Treatment, McGraw-Hill Book Co., (1979).

3. BARDI MURACHMAN, Flotasi Untuk Kursus Perancangan lnstalasi Pengolah Air Limbah lndustri, Jurusan Teknik Kimia, Fakultas Teknik, Universitas Gadjah Mada, Yogyakarta, 16 - 28 Januari 1995.

4. ROBERT H.PERRY AND DON W.GREEN, Perry's Chemical Engineers, Handbook, . Seventh Edition, MC Graw Hill Companies, Inc., (1997).

5. RICHARD P.H., AMIR E., TUKARDI, SRI SUDARYANTO,. Pemisahan Molibdenit Dari Bijih Uranium Rirang Secara Flotasi, Prosiding Seminar Pranata Nuklir dan Litkayasa, PPBGNBATAN, Jakarta, 2 September (1998).

6. Http://www.exploratorium.edu/ronh/bub bles/soap.html 